\title{
Aripiprazole in Autism Spectrum Disorders and Fragile X Syndrome
}

\author{
Craig A. Erickson, ${ }^{* \dagger}$ Kimberly A. Stigler, ${ }^{* \dagger}$ David J. Posey, ${ }^{* \dagger}$ and Christopher J. McDougle*t \\ *Department of Psychiatry, Indiana University School of Medicine, Indianapolis, Indiana, 46202; and ${ }^{\dagger}$ Christian Sarkine Autism \\ Treatment Center, James Whitcomb Riley Hospital for Children, Indianapolis, Indiana 46202
}

\begin{abstract}
Summary: Autism spectrum disorders (ASDs) are childhood onset developmental disorders characterized by impairment of social skills and repetitive behavior, and also for classic autistic disorder, a significant impairment of communication. In addition to these core symptom domains, persons with ASDs frequently exhibit interfering behavioral symptoms, including irritability marked by aggression, self-injurious behavior, and severe tantrums. Aripiprazole is an atypical or newer generation antipsychotic with a unique mechanism of action impacting dopaminergic and serotonergic neurotransmission. The drug has been found efficacious for several indications, includ-
\end{abstract}

ing most recently for use targeting irritability associated with autistic disorder in youth. Fragile $\mathrm{X}$ syndrome is the most common inherited cause of developmental disability and the most common known single gene cause of ASDs. As in idiopathic ASDs, irritable behavior is often exhibited by persons with fragile $\mathrm{X}$ syndrome. However, research to date in this disorder has not focused on this target symptom cluster. An initial pilot study has begun to assess the impact of aripiprazole on irritability in youth with fragile X syndrome. Key Words: Aripiprazole, autistic disorder, irritability, fragile $\mathrm{X}$ syndrome.

\section{INTRODUCTION}

Autism spectrum disorders (ASDs) are a group of childhood onset developmental disorders unified by a significant delay in the development of age-appropriate social skills. ASDs include autistic disorder, pervasive developmental disorder, not otherwise specified (PDDNOS), and Asperger's disorder (also known as Asperger's syndrome). Autistic disorder (autism) is the prototypical ASD. Persons with autism suffer from significant social impairment, language/communication delay, and interfering repetitive behavior with onset of symptoms in at least one domain prior to 3 years of age. ${ }^{1}$ The combined prevalence of ASDs is estimated to be as high as 1 in 91 persons in the United States. ${ }^{2}$ In addition to core impairments, youth with ASDs frequently exhibit interfering irritability marked by aggression, self-injurious behavior, and severe tantrums. Irritability has a significant impact on the individual and the family, and this can limit access to important educational, vocational, and

Address correspondence and reprint requests to: Craig A. Erickson, M.D., Department of Psychiatry, Indiana University School of Medicine, 702 Barnhill Drive, Room 4300, Indianapolis, IN 46202. E-mail: crericks@iupui.edu. other services. ${ }^{3}$ Given this impact, research in the last 2 decades has focused on the pharmacologic treatment of irritability associated with ASDs. Among drug classes, the atypical or newer generation antipsychotics have been the most studied drug class targeting irritability in ASDs. ${ }^{3}$ Among atypical antipsychotics, the efficacy of risperidone and aripiprazole has been recognized by the United States Food and Drug Administration (FDA); approvals have been made to treat children and adolescents who have autism (age range, 5 to 16 years) with risperidone and children who have associated irritability (age range, 6 to 17 years) with aripiprazole. Generally, reports on the use of other atypical antipsychotics, including clozapine, olanzapine, quetiapine, or ziprasidone have noted less efficacy and/or more significant treatment-limiting adverse effects (weight gain, sedation, prolonged cardiac QTc interval) than the use of risperidone or aripiprazole in autism. ${ }^{3}$

Fragile X syndrome (FXS) is the most common inherited form of developmental disability and the most common single gene causing ASDs. FXS is associated with a particular neurobehavioral phenotype marked by interfering behavioral symptoms, including irritability, outof-proportion to cognitive level. ${ }^{4}$ FXS overlaps significantly with ASDs with 1 in 3 to 4 males who have FXS 
meeting autistic disorder criteria and as many as 2 to 3 males who have FXS meeting criteria for the broader ASD phenotype. ${ }^{5-7}$ Variation in the report of the rate ASD comorbid with FXS probably results from variation in the ascertainment of ASD diagnosis ranging from the use of standardized diagnostic measures to parent report. Persons with FXS to date have generally been excluded from the growing number of research studies designed to evaluate treatment options for interfering behaviors, including irritability associated with ASDs. ${ }^{8}$ The stress of irritability on the family is particularly magnified in FXS given that premutation carrier mothers are themselves at increased risk of anxiety and depressive disorders and behavioral disinhibition. ${ }^{9-11}$ As with idiopathic ASDs, atypical antipsychotics have been the most commonly used drug class to target irritability associated with FXS in clinical practice. ${ }^{8}$ A recent report noted that $50 \%$ of young adult males with FXS required antipsychotic treatment targeting irritability. ${ }^{4}$ Despite the common use of this drug class in FXS, no controlled drug trials of atypical antipsychotics have occurred in FXS, and only aripiprazole has been the subject of a systematic prospective pilot study targeting irritability associated with FXS.

This article will provide an overview of aripiprazole, including discussion of the mechanism of action of the drug. This will be followed by a comprehensive review of recent research focused on the use of aripiprazole in idiopathic ASDs. Emphasis will be placed on comparison of the tolerability and efficacy of aripiprazole compared with risperidone, which is the other FDA-approved drug for use in treating autism. Finally, we will discuss an ongoing pilot study of aripiprazole in FXS being conducted by our group.

\section{OVERVIEW OF ARIPIPRAZOLE}

Aripiprazole is a novel agent that differs in mechanism of action from other available antipsychotic drugs. ${ }^{12}$ The compound is a partial dopamine (DA) $\mathrm{D}_{2}$ and 5- $\mathrm{HT}_{1 \mathrm{~A}}$ agonist, and a 5- $\mathrm{HT}_{2 \mathrm{~A}}$ antagonist. ${ }^{13,14}$ Aripiprazole has a significantly higher affinity for the DA $\mathrm{D}_{2}$ receptor than other available atypical antipsychotic drugs. ${ }^{15}$ However, in contrast to the currently available typical and atypical antipsychotics that are $\mathrm{DA} \mathrm{D}_{2}$ receptor antagonists, aripiprazole is a partial agonist at the $\mathrm{DA} \mathrm{D}_{2}$ receptor. Thus, the drug antagonizes the DA $\mathrm{D}_{2}$ receptor site under hyperdopaminergic conditions, and is an agonist under hypodopaminergic conditions. ${ }^{16}$ Aripiprazole is hypothesized to function as an agonist or antagonist depending on the receptor population and local concentrations of DA. ${ }^{17}$ In addition to its mechanism of action as a potent DA $\mathrm{D}_{2}$ partial agonist, aripiprazole is a potent partial agonist at the $5-\mathrm{HT}_{1 \mathrm{~A}}$ receptor. ${ }^{14}$ Preclinical research has shown that the drug is a $5-\mathrm{HT}_{2 \mathrm{~A}}$ receptor antagonist, ${ }^{18}$ and it has also been demonstrated to be a $5-\mathrm{HT}_{2 \mathrm{C}}$ partial agonist and an inverse agonist at the 5- $\mathrm{HT}_{2 \mathrm{~B}}$ receptor.

The compound's unique pharmacology, which may underlie its efficacy in the treatment of positive and negative symptoms of schizophrenia, suggests it may also be effective in the treatment of a number of neuropsychiatric disorders. Aripiprazole has demonstrated efficacy associated with FDA approval for treatment of the following: schizophrenia in adults and adolescents, bipolar mania in adults and pediatric patients, agitation associated with schizophrenia or bipolar mania in adults, treatment of major depression in adults as an adjunct to antidepressants, and irritability associated with autistic disorder in youth. ${ }^{19}$

Aripiprazole is metabolized via the dehydrogenation, hydroxylation, and $\mathrm{N}$-dealkylation pathways. In vitro studies of aripiprazole demonstrate that dehydrogenation and hydroxylation occurs through the cytochrome P-450 (CYP) $3 \mathrm{~A} 4$ and CYP2D6 enzymes, and that N-dealkylation is catalyzed through the CYP3A4 enzyme. Because these CYP isoforms are involved in the metabolism of aripiprazole, inhibition of CYP3A4 (ketoconazole) or CYP2D6 (fluoxetine, paroxetine, or quinidine) enzymes can cause increased blood levels of aripiprazole. In addition, an increase in aripiprazole clearance can occur with agents such as carbamazepine that induce the CYP3A4 isoform. ${ }^{19}$

\section{ARIPIPRAZOLE IN ASDs}

Several open-label investigations have described aripiprazole treatment in youth with various ASDs. In 2004, Stigler et al. ${ }^{20}$ conducted one of the first pilot studies of aripiprazole in five youth (mean age, 12.2 years) with autism. In this prospective open-label case series, subjects received the drug (mean dosage, $12.0 \mathrm{mg} / \mathrm{day}$; range, $10-15 \mathrm{mg} /$ day) for a minimum of 8 weeks (mean duration, 12.8 weeks; range, $8-16$ weeks). Five of five subjects were deemed responders, as determined by a clinical global impressions improvement item (CGI-I) ${ }^{21}$ rating of "much improved" or "very much improved." Significant improvement was noted in a variety of interfering behavioral symptoms, including aggression, selfinjurious behavior, and irritability. Aripiprazole was well tolerated. No acute extrapyramidal symptoms (EPS) or changes in heart rate or blood pressure were recorded. Two of five subjects experienced mild transient somnolence. Two subjects lost weight, two had no change, and one subject gained $1 \mathrm{lb}$. (mean change, $-8.2 \mathrm{lbs}$.; range, -30 to $+1 \mathrm{lb}$.). The relative weight loss was hypothesized to be secondary to discontinuation of prior atypical antipsychotic treatments that had led to the significant weight gain.

A recent prospective 14-week, open-label study was conducted in 25 psychotropic medication-free youth aged 5 to 17 years (mean age, 8.6 years) with PDD-NOS 
$(\mathrm{n}=21)$ or Asperger's disorder $(\mathrm{n}=4) .{ }^{22}$ Twenty-two subjects $(88 \%)$ were considered aripiprazole responders (mean dose, $7.8 \mathrm{mg}$; range, $2.5-15 \mathrm{mg} /$ day) based on a CGI-I score of 1 ("very much improved") or 2 ("much improved") and a $\geq 25 \%$ improvement on the aberrant behavior checklist irritability subscale (ABC-I). ${ }^{23}$ Mean ABC-I scores improved significantly from 29 at baseline to 6.6 at week 14. Mild EPS were reported in 9 subjects $(36 \%)$ and age- and sex-normed body mass index increased significantly from a mean at baseline of 20.3 to 21.1 at end point. Serum prolactin levels decreased significantly during the study. No subject exited the study early due to a drug-related adverse event. This is the only report to date on the systematic use of aripiprazole in a well-characterized sample of youth with PDD-NOS or Asperger's disorder.

In a retrospective review of treatment (mean duration, 6.1 months) in a heterogeneous group of 32 developmentally disabled children (24 with an ASD and 18 with intellectual disability) aged 5 to 19 years, aripiprazole use (mean maintenance dose, $10.5 \mathrm{mg} /$ day) was associated with improvement in target symptoms, including aggression, self-injurious behavior, hyperactivity, and impulsivity in 18 subjects (56\% of cases) and 9 youth specifically with an ASD (38\%). ${ }^{24}$ The drug was discontinued in $22 \%$ of total cases within 2 weeks of aripiprazole initiation due to adverse effects, which included sleepiness $(n=4)$, myalgia $(n=1)$, facial dyskinesia $(n=1)$, increased aggression $(n=2)$, stiffness $(n=1)$, and diarrhea $(\mathrm{n}=1)$. Mean body mass index increased significantly during the treatment review period from 22.5 at baseline to 24.1 at end point.

In a naturalistic review of aripiprazole monotherapy in 34 inpatient youth (mean age, 10.2 years; range, 4.5-15 years) with various ASDs, drug use was associated with significant treatment response targeting maladaptive behavior in 11 subjects (32\%) during a mean of 7 months of treatment. ${ }^{25}$ Twelve patients (35\%) discontinued treatment during follow-up due to lack of drug effectiveness or adverse effects. Agitation and insomnia were the most frequently reported adverse effects.

The efficacy and safety of aripiprazole targeting irritability associated with autistic disorder in youth have been assessed in two industry funded double-blind, placebo-controlled 8-week studies. ${ }^{26,27}$ These studies, which were reviewed prior to the drug's FDA approval for this indication, include a fixed-dose study ( $\mathrm{n}=$ $218)^{27}$ and a flexible-dosed study $(\mathrm{n}=98)^{26}$ in youth with autism aged 6 to 17 years. In the fixed-dose study, all aripiprazole doses $(5,10$, or $15 \mathrm{mg} /$ day $)$ were associated with significantly greater improvement in mean $\mathrm{ABC}-\mathrm{I}$ and CGI-I scores compared to a placebo. ${ }^{27}$ Discontinuation rates from adverse effects of aripiprazole ranged from $7.4 \%$ to $13.6 \%$ with highest discontinuation levels at the $10 \mathrm{mg} /$ day dose. The most common adverse effect leading to discontinuation was sedation. Mean weight gain ranged from 1.3 to $1.5 \mathrm{~kg}$ /day during drug treatment. In the flexible-dosed study, aripiprazole (mean final dose, $8.9 \mathrm{mg} /$ day; range, $2-15 \mathrm{mg}$ /day) was associated with significant improvement in ABC-I and CGI-I scores compared to a placebo. ${ }^{26}$ In this report, the mean weight gain was $2.0 \mathrm{~kg}$ on aripiprazole compared to 0.8 $\mathrm{kg}$ on a placebo at week 8 .

Several post-hoc analyses of pooled data from the two controlled aripiprazole trials have been conducted. These reports provide additional information on the effectiveness and tolerability of the drug in youth with autistic disorder. A line-item analysis of ABC-I data found that the overall improvement in ABC-I total scores noted with aripiprazole treatment was primarily due to improvement in behaviors related to tantrums (yelling, cries/screams inappropriately, mood changes quickly, and temper tantrums). ${ }^{28} \mathrm{~A}$ second analysis looked at the impact of cognitive ability on aripiprazole treatment response. ${ }^{29}$ Overall aripiprazole was efficacious in the pooled data set in subsets of youth with above average, average, mildly impaired, or moderately impaired cognitive ability, but smaller nonsignificant improvement was noted in youth with severe cognitive impairment $(\mathrm{n}=27){ }^{29}$

A post-hoc analysis of drug safety and tolerability included 212 youth receiving active drug and 101 receiving a placebo for more than 8 weeks of blinded treatment. ${ }^{30}$ Overall, EPS rates were similar between treated youth who were aged 6 to 12 years and those youth who were aged 13 to 17 years. The overall EPS rate was $20.8 \%$ for all aripiprazole-treated patients versus $9.9 \%$ for a placebo. Metabolic and glucose measures remained stable during treatment, and significant weight gain occurred with aripiprazole treatment marked by an average increase in body mass index of 0.7 after 8 weeks. The most commonly reported adverse effects in the treatment group included sedation (20.8\%), somnolence (10.4\%), tremor $(9.9 \%)$, and drooling $(9.0 \%){ }^{31-33}$

Studies similar to the double-blind, placebo-controlled published trials of aripiprazole treatment for youth with autism have been conducted using the atypical antipsychotic risperidone. ${ }^{31,32}$ In 2002, the Research Units on Pediatric Psychopharmacology (RUPP) autism network conducted an 8-week double-blind, placebo controlled flexible-dosed trial of risperidone (mean dose, $1.8 \mathrm{mg} /$ day) in 101 youth (mean age, 8.8 years) with autistic disorder. ${ }^{31}$ A subsequent similar double-blind, placebocontrolled trial of risperidone (mean dose, $1.2 \mathrm{mg} /$ day) was conducted in Canada with 79 youth (mean age, 7.5 years) who had an ASD. ${ }^{32}$ As with the aripiprazole trials that were reviewed (as previously mentioned), both risperidone trials noted treatment associated improvement on the CGI-I and ABC-I during 8 weeks of treatment. ${ }^{31,32}$ The RUPP risperidone trial and the flexible- 
Table 1. FDA Approved Drugs for Irritability Associated with Autism: Tolerability Comparison

\begin{tabular}{|c|c|c|}
\hline Adverse Effect & $\begin{array}{l}\text { Risperidone } \\
\text { Trials } *, \dagger, \ddagger\end{array}$ & $\begin{array}{c}\text { Pooled Aripiprazole } \\
\text { Trial Data }\end{array}$ \\
\hline EPS & $0 \% *-28 \%$ * & $20.8 \%$ \\
\hline Mean weight gain & $2.7 \mathrm{~kg}^{*} \ddagger$ & $1.6 \mathrm{~kg}$ \\
\hline $\begin{array}{l}\text { Somnolence or } \\
\text { sedation }\end{array}$ & $59 \% *-72 \%$ & $31.2 \%$ \\
\hline $\begin{array}{l}\text { Change in serum } \\
\text { prolactin }\end{array}$ & 4-fold increase ${ }^{\dagger}$ & $\begin{array}{c}\text { Significant reduction } \\
\text { vs. placebo }\end{array}$ \\
\hline
\end{tabular}

EPS $=$ extrapyramidal symptoms; FDA $=$ United States Food and Drug Administration.

*McCracken JT, McGough J, Shah B, et al. Risperidone in children with autism and serious behavioral problems. N Engl J Med 2002; 347:314-321.

${ }^{\dagger}$ Anderson GM, Scahill L, McCracken JT, et al. Effects of shortand long-term risperidone treatment on prolactin levels in children with autism. Biol Psychiatry 2007;61:545-550.

${ }^{\ddagger}$ Shea S, Turgay A, Carroll A, et al. Risperidone in the treatment of disruptive behavioral symptoms in children with autistic and other pervasive developmental disorders. Pediatrics 2004;114:e634e641.

${ }^{\S}$ Robb A, Rojas-Fernandez C, Mankoski R, et al. Safety and tolerability of aripiprazole in the treatment of irritability associated with autistic disorder. In: 56th American Academy of Child and Adolescent Psychiatry Meeting. Honolulu, HI, 2009.

dosed aripiprazole study compared most favorably regarding study design and enrolled population. The effect size of the reduction on the ABC-I in the RUPP report was 1.2 compared to 0.87 reported by Owen et al. ${ }^{26}$ in 2009 in the aripiprazole study. This difference points to the potential for risperidone to have a more significant impact on irritability associated with autistic disorder in youth. Regarding potential treatment effect beyond irritability, neither risperidone nor ariprazole has been associated with improvement in social or communication impairment in youth with autism.

Regarding tolerability, pooled data from the controlled aripiprazole trials point to potential advantages compared with risperidone (Table 1). Comparison of these four trials suggests that risperidone is more sedating than aripiprazole, a finding consistent with our clinical experience. Both controlled risperidone trials reviewed for FDA approval of this drug reported more treatment associated weight gain $(2.7 \mathrm{~kg})$ during the 8 -week treatment than the $1.6 \mathrm{~kg}$ weight gain noted in the pooled ariprazole data. This result is also consistent with our clinical experience that aripiprazole may be associated with less weight gain than risperidone in youth with autism. In addition, it is clear that prolactin elevation frequently occurs with risperidone use in youth with autistic disorder ${ }^{33}$ compared to prolactin reduction noted in both aripiprazole controlled trials. ${ }^{26,27}$ Overall, EPS rates appear potentially similar between both risperidone and aripiprazole in the controlled trials reviewed for FDA approval, but this analysis is confounded by the
RUPP Autism Network report of no treatment-associated EPS by direct physician examination. ${ }^{31}$

\section{ARIPIPRAZOLE IN FRAGILE X SYNDROME}

Although atypical antipsychotic use is common in FXS targeting irritability, there is a dearth of published data supporting this use. Currently, only published chart reviews have described atypical antipsychotic use in FXS. Of 136 males seen at an FXS clinic (in Chicago, IL), among the males age 18 years and older, nearly 50\% were taking an atypical antipsychotic compared with just less than $20 \%$ of males ages 5 to 17 years. ${ }^{4}$ In the Chicago report, atypical antipsychotic use was lower in 40 female patients, with 10 to $20 \%$ of these individuals being treated with this class of drug. Available data indicated that 19 of 26 males with FXS who were treated with various atypical antipsychotics had a positive clinical response. ${ }^{4}$ In a clinic population survey of 262 individuals with FXS (in Denver, CO), approximately 10 to $20 \%$ of all patients were treated with atypical antipsychotics, with relatively more frequent use in male patients. ${ }^{34}$ A review of clinical experience in use of aripiprazole in FXS noted that lower dosing of aripiprazole (2.5-5.0 mg/day) worked best, even with lower dosing used in younger children secondary to agitation frequently reported at higher dosing. ${ }^{35}$

Given the lack of available information describing the safety and tolerability of atypical antipsychotics in FXS, our group initiated a prospective 12-week, open-label pilot study of aripiprazole in 12 persons (aged 6-35 years) with full mutation FXS. ${ }^{36}$ We chose aripiprazole for use in the first systematic atypical antipsychotic study in FXS given anecdotal reports of aripiprazole treatment success in this population and our positive experience with the drug in idiopathic ASDs. In our study, subjects were required to be free of all psychotropic medications, with the exception of drugs given at bedtime targeting insomnia and the use of anticonvulsants targeting seizure disorder. In addition, subjects were required to have a clinical global impression-severity score of at least 4 (moderately impaired) and a score of $\geq 18$ on the ABC-I. All subjects initially received $2.5 \mathrm{mg}$ /day of aripiprazole. The investigators increased the dosage to a maximum of $20 \mathrm{mg} /$ day for 8 weeks. Primary outcome measures included the parent-rated ABC-I, and the clinician-rated CGI-I item. To date, eight subjects have completed the study. The eight subjects include 1 female and 7 males (age range, 11 to 21 years; mean, 14 years). The final dosage of aripiprazole ranged from 7.5 to $20 \mathrm{mg}$ /day (mean, $14.6 \mathrm{mg} /$ day). All subjects to date have responded to treatment based on a CGI-I score of 1 or 2 ("very much" or "much improved") and a $\geq 25 \%$ improvement on the ABC-I subscale. In addition, all eight subjects had $\mathrm{a} \geq 25 \%$ improvement on the ABC-hyperactivity sub- 
scale that occurred with treatment. Aripiprazole has been well tolerated. No symptoms of tardive dyskinesia or EPS have been noted. Six subjects have lost weight during the study (mean weight change, $-4.8 \mathrm{lbs}$.; range, -13.9 to +6.6 lbs.), which was likely a result of discontinuing prior treatment with other atypical antipsychotics. Our initial data suggests that aripiprazole may be effective and well-tolerated as a treatment for irritability associated with FXS.

\section{CONCLUSION}

Recent research has assessed the efficacy and tolerability of aripiprazole targeting irritability associated with autistic disorder in youth. Comparisons of this work have been conducted with previous trials leading to FDA approval for use of risperidone for the same indication point to the potential for risperidone to have a more robust treatment effect in reducing irritability, whereas aripiprazole may potentially be better tolerated with regard to sedation, weight gain, and prolactin change.

Future work is necessary to continue refined understanding of the impact of aripiprazole in both idiopathic ASDs and FXS. Comparing the results from potential controlled studies of FXS to previous work in idiopathic ASDs will allow for determination of whether the presence of FXS in addition to an ASD diagnosis modulates treatment response. The unique mechanism of action of aripiprazole at the $\mathrm{DA}_{2}$ receptor may contribute to the early findings of potential substantial improvement in hyperactivity noted in our pilot study in FXS. Given the 5HT and DA effects of aripiprazole, combined with the potential implication of dopaminergic and serotonergic dysregulation in the neurobiology of $\mathrm{ASDs},{ }^{37}$ will be important in the future to thoroughly assess the impact of aripiprazole treatment on core symptoms of ASDs including social behavior and communication.

In autistic disorder, future work will benefit from study designs allowing for longer term assessment of tolerability combined with potential investigation of coactive medication treatment. As a targeted treatment for irritability associated with autistic disorder, aripiprazole will likely be prescribed with other concomitant medications targeting other specific behaviors, including potential future drugs developed for core social and communication impairments of ASDs. Additional investigations in adult populations of persons with ASDs are also warranted. Use of functional neuroimaging preand post-treatment in future ASD trials will contribute to the understanding of the underlying neurobiology of the disorders while also elucidating the impact of aripiprazole on brain activity and connectivity in these populations. Our group is addressing some of these needs by conducting a National Institute of Mental Health funded double-blind, placebo-controlled trial of aripiprazole tar- geting irritability in youth ages 5 to 17 years who have autism, which includes a pilot functional MRI component and a second study phase for aripiprazole responders using coactive treatment with the glutamatergic agent D-cycloserine targeting core social impairment. ${ }^{38}$

Although aripiprazole has been established as being efficacious for irritability in youth with autism, research focused on the use of aripiprazole in persons with the broader ASD phenotype is needed. No published controlled studies to date have assessed the use of aripiprazole in persons with PDD-NOS or Asperger's disorder. Our group is addressing this need by conducting an ongoing double-blind, placebo-controlled study of aripiprazole in youth with PDD-NOS aged 5 to 17 years. ${ }^{39}$

In FXS, our preliminary pilot data points to the potential of aripiprazole to be well tolerated and effective in reducing irritability in this population. Aripiprazole warrants controlled study in this population. Future study of aripiprazole in FXS will likely require a multi-site trial design given the relative rarity of the disorder.

\section{Dislosure}

Supported in part by The Division of Disability \& Rehabilitative Services, Indiana Family and Social Services Administration (Dr. Erickson and Dr. McDougle); National Institute of Health grant no. K12 UL1 RR025761, University Clinical and Translational Sciences Institute Career Development Award (Dr. Erickson); and NIMH grant no. 72964 (Dr. McDougle). Dr. Erickson receives research support from F. HoffmannLaRoche, Bristol-Myers Squibb Co., and Seaside Therapeutics. Dr. Erickson was previously a consultant for F. Hoffmann-LaRoche. Dr. McDougle receives research support from Bristol-Myers Squibb Co. Dr. McDougle is also a consultant for Bristol-Myers Squibb Co., F- Hoffmann-LaRoche, and Forest Research Institute. Dr. McDougle is on the Speakers' Bureau for Bristol-Myers Squibb, Co. Dr. Posey currently receives research support from Forest Pharmaceuticals, Johnson \& Johnson, and Eli Lilly \& Company. Dr. Posey was a past consultant for Bristol-Myers Squibb.

\section{REFERENCES}

1. American Psychiatric Association. Diagnostic and Statistical Manual of Mental Disorders, 4th Ed, text revision. Washington, D.C.: American Psychiatric Association; 2000.

2. Kogan MD, Blumberg SJ, Schieve LA, et al. Prevalence of parentreported diagnosis of autism spectrum disorder among children in the US, 2007. Pediatrics 2009;124:1395-1403.

3. Erickson CA, Posey DJ, Stigler KA, McDougle CJ. Pharmacologic treatment of autism and related disorders. Pediatr Ann 2007;36: 575-585.

4. Berry-Kravis E, Potanos K. Psychopharmacology in fragile X syndrome--present and future. Ment Retard Dev Disabil Res Rev 2004;10:42-48.

5. Hatton DD, Sideris J, Skinner M, et al. Autistic behavior in children with fragile $\mathrm{X}$ syndrome: prevalence, stability, and the impact of FMRP. Am J Med Genet A 2006;140A:1804-1813. 
6. Bailey DB, Jr., Hatton DD, Skinner M, Mesibov G. Autistic behavior, FMR1 protein, and developmental trajectories in young males with fragile X syndrome. J Autism Dev Disord 2001;31: 165-174.

7. Bailey DB, Jr., Raspa M, Olmsted M, Holiday DB. Co-occurring conditions associated with FMR1 gene variations: findings from a national parent survey. Am J Med Genet A 2008;146A(16):20602069.

8. Erickson CA, Stigler KA, Posey D, McDougle C. Managing maladaptive behaviors in fragile $\mathrm{X}$ patients. Curr Psychiatry 2006;5: $80-92$.

9. Hessl D, Rivera S, Koldewyn K, et al. Amygdala dysfunction in men with the fragile X premutation. Brain 2007;130(Pt 2):404416.

10. Hessl D, Tassone F, Loesch DZ, et al. Abnormal elevation of FMR1 mRNA is associated with psychological symptoms in individuals with the fragile X premutation. Am J Med Genet B Neuropsychiatr Genet 2005;139B(1):115-121.

11. Johnston C, Eliez S, Dyer-Friedman J, et al. Neurobehavioral phenotype in carriers of the fragile X premutation. Am J Med Genet 2001;103:314-319.

12. Shapiro DA, Renock S, Arrington E, et al. Aripiprazole, a novel atypical antipsychotic drug with a unique and robust pharmacology. Neuropsychopharmacology 2003;28:1400-1411.

13. Burris KD, Molski TF, Xu C, et al. Aripiprazole, a novel antipsychotic, is a high-affinity partial agonist at human dopamine D2 receptors. J Pharmacol Exp Ther 2002;302:381-389.

14. Jordan S, Koprivica V, Chen R, Tottori K, Kikuchi T, Altar CA. The antipsychotic aripiprazole is a potent, partial agonist at the human 5-HT1A receptor. Eur J Pharmacol 2002;441:137-140.

15. Arnt J, Skarsfeldt T. Do novel antipsychotics have similar pharmacological characteristics? A review of the evidence. Neuropsychopharmacology 1998;18:63-101.

16. Kikuchi T, Tottori K, Uwahodo Y, et al. 7-(4-[4-(2,3-Dichlorophenyl)-1-piperazinyl]butyloxy)-3,4-dihydro-2(1H)-qui nolinone (OPC-14597), a new putative antipsychotic drug with both presynaptic dopamine autoreceptor agonistic activity and postsynaptic D2 receptor antagonistic activity. J Pharmacol Exp Ther 1995;274: 329-336.

17. Inoue A, Nakata Y. Strategy for modulation of central dopamine transmission based on the partial agonist concept in schizophrenia therapy. Jpn J Pharmacol 2001;86:376-380.

18. Casey DE, Carson WH, Saha AR, et al. Switching patients to aripiprazole from other antipsychotic agents: a multicenter randomized study. Psychopharmacology (Berl) 2003;166:391-399.

19. Bristol-Myers_Squibb, Otsuka_America_Pharmaceutical_Inc. Aripiprazole prescribing information. Otsuka Pharmaceuticals Co., Ltd. Tokyo: Otsuka Pharmaceuticals Co., Ltd.; 2009:1-77.

20. Stigler KA, Posey DJ, McDougle CJ. Aripiprazole for maladaptive behavior in pervasive developmental disorders. J Child Adolesc Psychopharmacol. Fall 2004;14:455-463.

21. Guy W. ECDEU assessment manual for psychopharmacology, Publication No. 76-338. Washington, DC: U.S. DHEW, NIMH; 1976.

22. Stigler KA, Diener JT, Kohn AE, et al. Aripiprazole in pervasive developmental disorder not otherwise specified and Asperger's disorder: a 14-week, prospective, open-label study. J Child Adolesc Psychopharmacol 2009;19:265-274.
23. Aman MG, Singh NN, Stewart AW, Field CJ. The aberrant behavior checklist: a behavior rating scale for the assessment of treatment effects. Am J Ment Defic 1985;5:485-491.

24. Valicenti-McDermott MR, Demb H. Clinical effects and adverse reactions of off-label use of aripiprazole in children and adolescents with developmental disabilities. J Child Adolesc Psychopharmacol 2006;16:549-560.

25. Masi G, Cosenza A, Millepiedi S, Muratori F, Pari C, Salvadori F. Aripiprazole monotherapy in children and young adolescents with pervasive developmental disorders: a retrospective study. CNS Drugs 2009;23:511-521.

26. Owen R, Sikich L, Marcus RN, et al. Aripiprazole in the treatment of irritability in children and adolescents with autistic disorder. Pediatrics 2009;124:1533-1540.

27. Marcus RN, Owen R, Kamen L, et al. A placebo-controlled, fixeddose study of aripiprazole in children and adolescents with irritability associated with autistic disorder. J Am Acad Child Adolesc Psychiatry 2009;48:1110-1119.

28. Aman MG, Kasper W, Manos G, et al. Aripiprazole in the treatment of irritability associated with autistic disorder in children and adolescents (6-17 years old): Line-item analysis of the Aberrant Behavior Checklist Irritability Subscale. 56th American Academy of Child \& Adolescent Psychiatry Meeting. Honolulu, HI; 2009.

29. Mankoski R, Manos G, Chambers J, et al. Effect of cognitive ability on aripiprazole treatment of irritability associated with autistic disorder. 56th American Academy of Child \& Adolescent Psychiatry Meeting. Honolulu, HI; 2009.

30. Robb A, Rojas-Fernandez C, Mankoski R, et al. Safety and tolerability of aripiprazole in the treatment of irritability associated with autistic disorder. 56th American Academy of Child and Adolescent Psychiatry Meeting. Honolulu, HI; 2009.

31. McCracken JT, McGough J, Shah B, et al. Risperidone in children with autism and serious behavioral problems. N Engl J Med 2002; 347:314-321.

32. Shea S, Turgay A, Carroll A, et al. Risperidone in the treatment of disruptive behavioral symptoms in children with autistic and other pervasive developmental disorders. Pediatrics 2004;114:e634641

33. Anderson GM, Scahill L, McCracken JT, et al. Effects of shortand long-term risperidone treatment on prolactin levels in children with autism. Biol Psychiatry 2007;61:545-550.

34. Amaria R, LL B, R H. Medication use in fragile X syndrome. Mental Health Asp Dev Dis 2001;4:89-93.

35. Hagerman RJ, Berry-Kravis E, Kaufmann WE, et al. Advances in the treatment of fragile $X$ syndrome. Pediatrics 2009;123:378390.

36. Erickson CA, Mullett J, Diener JT, et al. Open-label aripiprazole in Fragile X Syndrome. National Clinical and Translational Research Annual Meeting. Washington, D.C.; 2009.

37. McDougle CJ, Erickson CA, Stigler KA, Posey DJ. Neurochemistry in the pathophysiology of autism. J Clin Psychiatry 2005; 66(suppl 10): $9-18$

38. United States National Institutes of Health. Clinicaltrials.gov. Available at: http://www.clinicaltrials.gov/ct2/show/NCT00198107. Accessed February $9,2010$.

39. United States National Institutes of Health. Clinicaltrials.gov. Available at: http://www.clinicaltrials.gov/ct2/show/NCT00870727. Accessed February $9,2010$. 